\title{
An Analysis of Popular Science Policy in China Based on the Policy Instrument Perspective
}

\author{
D.-Y.-KONG
}

School of Humanities \& Law, Northeastern University, Shenyang 110819, China

\begin{abstract}
Using the content analysis, taking the policies about popular science policy at national level in China as samples, the research makes a quantitative analysis on the popular science policy instrument, in accordance with the building analytical framework, defining the unit of analysis, code classification reliability analysis and frequency statistics, analysize the problems existing in the policy instruments selection and use of popular science policy using the way of content analysis. And then propose suggestions for the existing problems in rationality, so as to improve the optimization of popular science policy by giving the theoretical basis.
\end{abstract}

Keywords - policy instrument, popular science policy, content analysis, frequency statistics

\section{政策工具视域下的我国科普政策文本内容分析}

\author{
孔德意 \\ 东北大学文法学院, 沈阳, 辽宁, 中国
}

摘 要 本文采用内容分析法, 以我国国家层面颁布的专门性科普政策文本为样本, 按照构建政策分析框架、确定分析单元、编 码归类、信度分析、频数统计等步骤对我国科普政策工具进行量化分析, 深入剖析科普政策在政策工具选择和运用中存在的问题。针 对所存在的问题提出合理性政策建议，旨在为完善和优化我国科普政策提供理论依据。

关键词 政策工具, 科普政策, 内容分析法, 频数统计

1. 引言

当前，科学技术的迅猛发展深刻影响了我国社会和经 济的发展, 科技创新对社会经济的促进作用日益显著, 科 学研究、技术创新和社会进步的一体化发展之势日趋明显, 创新驱动发展的新阶段已经到来, 创新型国家建设已成为 时代发展主旋律。“在创新型国家建设中, 科技创新与科学 普及发挥着重要的基础作用” [1]。科普政策作为调节科普 资源的有力杜杆, 其制定是否科学、体系是否完善对于能 否营造出良好的科学传播环境、促进科普事业高速发展及 提高我国公民科学素质产生直接影响。“这里的科普政策, 指的是各级立法机关和政府颁布的与科学技术普及相关的 法律、法规、规章、条例和政策性文件”[2]。从相关性上 看, 科普政策又分为专门科普政策和相关科普政策, “专 门科普政策”是指专门针对科普制定的有关政策。“相关科 普政策, 是指虽不是专门的科普政策, 但政策内容涉及科普 工作的很多方面, 如《发展规划纲要》中涉及很多科普工 作的内容和要求”[3]。近几十年来, 随着我国政府职能的
拓展, 政策制定和实施等方面复杂性程度的加深, 日益需 要提升政策制定者的科学决断力。在这一背景下, 本文基 于政策工具视域对我国科普政策进行考量, 对于科普政策 质量的改进以及为政策制定者提供参考借鉴具有重要价 值。

\section{2. 研究设计}

\section{1 研究方法}

“内容分析法是指对于文献内容进行系统的定量与定 性相结合的一种语言分析方法”[4], “是以文本内容为分析 对象的量化研究方法。通过量化分析特定词语和概念在文 本或文本集中出现的频次、含义和相互之间的关系, 来推 断文本、作者、受众及其文化和时代背景所蕴含的信息与 启示”[5]。内容分析法具有客观性强、易于操作、能对文 本进行批量处理、揭露随意观察文本时难以发掘信息等优 点, 在图书情报学、传播学、政策分析等领域有着较为广 
泛的应用。随着我国对内容分析法和政策工具的深入研究, 将两者将结合对某些政策领域进行研究也越发广泛。如陈 衍泰等[6]采用内容分析法, 以新能源汽车产业为例, 对我 国中央、地方政府出台的新能源汽车产业政策进行计量分 析和评价。深入剖析我国新能源汽车产业政策所存在的问 题, 并为未来新能源汽车产业政策的完善和优化提出建议。 胡赛全等[7]从政策工具体系角度出发, 以我国31个省市关 于战略性新兴产业发展的政策文本为样本, 采用内容分析 法对政策文本中的关键词进行编码和量化分析。研究发现 我国战略性新兴产业发展的政策工具体系由战略规划类、 组织保障类、具体措施类和政策支持类构成。本文采用内 容分析法对我国科普政策工具进行挖掘与探索, 为科学制 定和系统优化我国科普政策提供理论依据。

\section{2 研究步骤}

本文采用内容分析法对中国科普政策文本进行分析， 首先选择中央政府所颁布的科普政策文本作为研究样本, 并根据政策工具理论制定分析框架; 其次确定研究样本的 分析单元及构建类目，并对每项科普政策文本中的政策工 具内容进行编码和可靠性检验; 然后将符合框架的科普政 策编号归入分析框架中进行频数统计; 在此基础上最后得 出研究结论, 并对结论进行分析、推论和提出相关建议。

\section{3 数据来源及样本选择}

因地方政策通常具有地域性，本文对科普政策文本的 选择仅限于国家层面，地方政府颁布的相关政策文件不在 研究范围之内。本文以北大法律信息网中的“中央法规司法 解释数据库”为样本数据的主要来源。在检索过程中以“科 普”或“科学素质”为标题关键词进行模糊搜索, 发布时间节 点设为“1994-2013”，共检索出政策样本 272 份，并以“万 方学术期刊数据库”和相关国家部委网站为补充, 最后对采 集到的政策样本进行查重和规范处理, 最终得到科普政策 样本 311 份。为保证政策选取的准确性和代表性, 提高研 究针对性, 笔者对初步整理的 311 份政策文本按照以下标 准进行遴选, 一是与科学普及密切相关, 剔除了与科普政 策相关度不高的政策文本，如科普节目播出时间通知、个 人获奖名单通报、科普基地命名公告、会议和培训时间通 知等; 二是所检索的政策类型主要是法律法规、纲要、通 知、意见、规划、公告等文件, 如复函等其他文件不计入 政策分析文本。根据以上规则, 本文最终确定了国家层面 的政策样本 50 项。

\section{3. 基于政策工具的科普政策内容分析}

“政策工具是公共政策研究的一个重要路径, 是随政策
科学的兴起而展开的, 是政策过程分析在工具理性层面的 发展和深化。政策工具分析以政策的结构性为基本立论基 础, 认为政策是可以通过一系列基本的单元工具的合理组 合而建构出来的, 并认为政策工具反映了决策者的公共政 策价值和理念”[8]。基于政策工具视域建立我国科普政策 分析框架, 可以对我国科普政策工具的特点、规律和趋势 进行更深层次的把握, 因此, 本文将政策工具分析作为构 建科普政策分析框架的支点。本文结合 Rothwell 和 Zegveld[9]的思想, 将基本政策工具分为供给、环境和需求 三种类型。供给型政策工具主要体现为政策对科普事业的 推动力, 指政府通过对设施、信息、资金和服务等支持扩 大供给面, 改善科普事业相关要素的供给状况, 推动科普 事业可持续发展。供给型政策工具可分为资金投入、基础 设施建设和公共服务等方面。环境型政策工具主要体现为 科普政策对科普事业的影响力, 指政府通过税收优惠、法 规管制、财务金融等一系列工具进行政策调控, 为科普事 业发展提供良好的政策软、硬环境和发展空间。环境型政 策工具又可细分为目标规划、金融支持、法规管制、税收 优惠等方面。需求型政策工具指政府通过对科普事业的扶 助, 降低外部因素对科普的不良影响, 通过科普产业发展 夯实科普事业建设的阵地, 从而对科普事业发展进行有效 的牵引。需求型政策工具又可分为政府采购、服务外包、 贸易管制等方面。

\section{1 分析单元的定义和类目构建}

分析单元指的是计算的对象, 可以是一个字、一个词、 一段话、一个主题、一篇评论等。分析单元的选取主要是 基于实现研究目标所需的信息, 本文根据研究需要将研究 样本的具体条款作为分析单元。同时, 根据科普政策分析 框架构建分析类目, 构建分析类目应注意以下问题 [10], 第一, 设立的类目必须与研究目标紧密相关。第二, 设立 的类目应具有相应的功能, 即内容分析研究能说明信息传 播过程中的一些问题。第三, 类目体系应方便管理, 主要 是指类目数量应有一定的限制。本文构建分析类目如下: 政策工具维度一一供给型、环境型、需求型、人才培养、 信息支持、基础设施建设、资金投入、公共服务、目标规 划、金融支持、税收优惠、法规管制、策略性措施、政策 采购、外包、贸易管制。

\section{2 编码}

本文首先对已遴选出的 50 份政策文本按照政策的具 体条款进行编码, 然后根据已建立的科普政策基本工具分 析框架将其分别归类, 最终形成了基于政策工具的科普政 策文本内容分析单元编码表, 如表 1 所示 
表 1 内容分析单元编码表

\begin{tabular}{|c|c|c|c|c|}
\hline 编号 & 政策名称 & 内容分析单元 & 编码 & 归类 \\
\hline \multirow[t]{2}{*}{1} & \multirow{2}{*}{$\begin{array}{l}\text { 关于组织开展第三批 } \\
\text { 国土资源科普基地推 } \\
\text { 荐命名工作的通知 }\end{array}$} & $\begin{array}{l}\text { 国土资源部科技与国际合作司负责指导和协调, 国土资源科普基地管理办 } \\
\text { 公室 (以下简称“科普基地办”) 具体负责此次科普基地推荐工作。 }\end{array}$ & $1-2$ & 法规管制 \\
\hline & & 鼓励积极推荐土地领域或科研实验类科普基地。 & $1-3$ & 策略性措施 \\
\hline \multirow{3}{*}{2} & \multirow{3}{*}{$\begin{array}{c}\text { 关于成立全国高层次 } \\
\text { 科普专门人才培养指 } \\
\text { 导委员会的通知 }\end{array}$} & $\begin{array}{l}\text { 指导委员会是在教育部、中国科协领导下, 对高层次科普专门人才培养工 } \\
\text { 作提供研究咨询、指导和服务的专家组织。 }\end{array}$ & $2-1$ & 公共服务 \\
\hline & & $\begin{array}{l}\text { 指导委员会设秘书处。秘书处是指导委员会的工作机构, 负责指导委员会 } \\
\text { 的日常工作。秘书处挂靠中国科学技术馆。 }\end{array}$ & $2-4$ & 法规管制 \\
\hline & & $\begin{array}{l}\text { 请有关部门 (单位) 对指导委员会的工作给予大力支持。请秘书处挂靠单 } \\
\text { 位在工作人员配备、工作场所、活动经费等方面给予必要支持。 }\end{array}$ & $2-5$ & 资金投入 \\
\hline & & & & \\
\hline 49 & $\begin{array}{c}\text { 关于加强科普宣传工 } \\
\text { 作的通知 }\end{array}$ & $\begin{array}{l}\text { 对反映科技战线生活和人物的优秀作品, 对有较大反响的科技新闻报道及 } \\
\text { 各种科普作品, 要采取适当措施予以表彰。 }\end{array}$ & $49-10$ & 策略性措施 \\
\hline \multirow[t]{2}{*}{50} & \multirow[t]{2}{*}{$\begin{array}{l}\text { 中共中央、国务院关于 } \\
\text { 加强科学技术普及工 } \\
\text { 作的若干意见 }\end{array}$} & $\begin{array}{l}\text { 当前, 主要是把现有场馆设施改造和利用好, 充分发挥其效益。各省、自 } \\
\text { 治区、直辖市、特别是经济较发达地区, 应该尽可能地创造条件, 对现有 } \\
\text { 的科普设施进行改造, 使之逐步完善。 }\end{array}$ & $50-9$ & 基础设施建设 \\
\hline & & 各有关部门要研究制定加强和改善科普工的实施方案, 并认真督促执行。 & $50-13$ & 法规管制 \\
\hline
\end{tabular}

\section{3 可靠性检验}

可靠性检验既内容分析中的一致性信度分析。“一致性 越高, 内容分析的可信度也越高; 一致性越低, 则内容分 析的可信度越低, 它是保证内容分析结果可靠性、客观性 的重要指标”[11]。内容分析法的信度公式为:

$$
\mathrm{r}=\frac{2 M}{N_{1}+N_{2}}
$$

其中 $r$ 为平均相互同意度 (指两个评判员之间相互同意 的程度), $\mathrm{M}$ 为两者都完全同意的栏目, $N_{1}$ 为第一评判员 所分析的栏目数, $N_{2}$ 为第二评判员所分析的栏目数。本研 究的第二评判员分别对 50 份政策分析单元按照政策编码栏 目进行评判, 并与第一评判员的评判结果进行对比检验, 其中评判结果不一致标记为“0”, 否则标记“1”。然后通过 公式 (2) 得出内容分析的最终信度。

$$
R=\left(\sum_{\mathrm{i}=1}^{50} \mathrm{r}_{\mathrm{i}}\right) / 50
$$

根据计算得出评判结果为 $90.3 \%$, “根据 Nunnaly 的观 点, 信度程度在 0.7 以上时表示前期的研究足够可信”, ${ }^{[12]}$, 这证明评判结果通过了检验, 是可信的。

\section{4 频数统计}

科普政策在环境型、需求型和供给型政策工具中的运 用, 为科普事业发展起到了多方面的促进与激励作用, 但 是, 在具体政策工具运用上却呈现出明显的分化与差异。

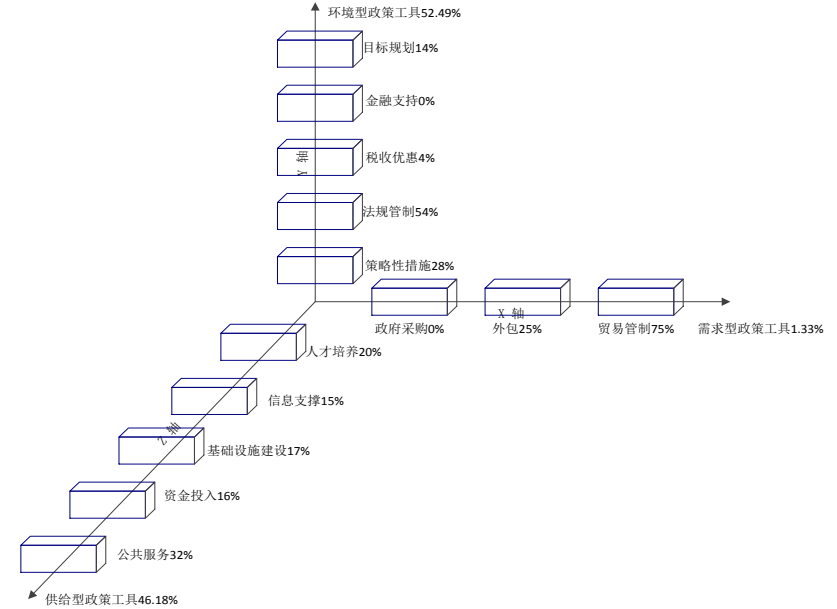

图 1 政策工具分布图

科普政策工具频数统计结果如图 1 所示, 按照条款项 目数计, 环境型政策工具使用频率最高, 占整体政策工具 的 $52.49 \%$, 供给型政策工具次之, 与环境型政策工具使用 频率差别不大, 为 $46.18 \%$, 最少的是需求型政策工具, 仅 仅为 $1.33 \%$ 。进一步挖掘发现, 在环境型政策工具中, 法 规管制一统半壁江山, 为 $54 \%$, 之后依次为策略性措施 $28 \%$, 目标规划 $14 \%$, 税收优惠 $4 \%$, 财务金融则未得到体 现。在供给型政策工具中, 除公共服务所占比例为 $32 \%$ 外, 其余各政策工具呈均衡之势，依次是人才培养 $20 \%$, 基础 设施建设 $17 \%$ ，资金投入 $16 \%$, 信息支撑 $15 \%$ 。在需求型 政策工具中, 仅有 3 条贸易管制工具和 1 条服务外包工具 得到了采用, 政府采购工具存在缺失现象。以上表明中央 
政府在科普政策工具选择上主要以环境型和供给型为主, 更倾向于使用间接影响和直接推动的策略, 但需求型政策 工具缺失直接导致对科普事业拉动力严重不足。

\section{4. 研究结论}

\section{1 环境型政策工具显分化之态}

通过统计不难看出, 环境型政策工具分化严重, 法规 管制与策略性措施使用过溢, 而税收优惠和财务金融等经 济激励工具存在匮乏与缺失情况, 环境型政策工具所呈现 的是两极分化之态势。法规管制是一种简单而有效的政策 工具, 是行政权力直接干预的具体表现, 法规管制的过溢 说明政府在政策工具选择和运用上对其具有偏爱性, 当科 普事业发展到一定程度后, 法规管制的过度使用会起到一 定的负作用。法规管制工具的频现, 简单、直接是其主要 原因，易使政策制定者对法规管制工具的运用逐渐形成一 种路径依赖。我国科普事业都处于探索阶段, 导致在政策 上使用了较多的策略性措施, 策略性措施频现反映了加强 科普环境建设的重要性与迫切性, 政府意在通过宏观政策 引导, 对科普事业发展大环境进行改善。但是, “策略性措 施实际上是一种短期行为, 对于像国家法规这样的文件来 说并不太适宜 ${ }^{\text {" }}$ [13]。财政金融作为科普事业快速发展的重要 推手和有力保障, 涉及低率贷款、财政贴息和分期付款等 内容。税收优惠的贵乏难以激励和吸引各类组织、团体、 企事业单位等社会资源对科普事业的投入, 阻碍了我国科 普凝聚力的加强和科普资源的共享。

\section{2 供给型政策工具呈均衡之势}

通过统计得出, 供给型政策工具的使用总体上呈现均 衡的态势。在供给型政策工具方面使用最频繁的是公共服 务, 公共服务使用比例最高主要有两点原因, 一是我国政 府在过去对科普提供的公共服务严重不足, 导致我国科普 事业发展的基础条件及能力、水平都还处于低级别层次, 意在着力加强; 二是我国科普事业发展对相应科普配套服 务措施需求加大所致。作为使用频率较高的政策工具, 供 给型政策工具间组合的结构性失衡情况并未出现, 说明政 府在供给型政策工具使用中基本“一视同仁”, 政策制定者 在人才培养、基础设施建设、资金投入、信息支撑和公共 服务上都有所兼顾。

\section{3 需求型政策工具突缺位之形}

从政策工具频数统计结果来看, 需求型政策工具应用缺 位和不足问题尤为凸显，仅仅占整体政策工具的 $1.33 \%$, 政府采购工具在需求型政策工具中未得到任何体现, 仍处 于一个真空状态, 服务外包、贸易管制这些政策工具也很 少涉及。需求型政策工具借助服务外包、政府采购、贸易
管制等形式从某种程度上确保了科普事业发展的持续性、 减少了科普事业发展的不稳定性, 其对科普的促进作用要 比环境型政策工具来得更为直接, 能缓解政府在财政、人 员等诸多方面的压力, 是促进科普事业发展的重要因子。 这些政策工具具有明确的指向性, 是促进科普事业发展的 快捷方式, 需求型政策工具的缺失与不足造成与实际操作 层面的断裂，从而弱化了政策整体的牵引作用。

\section{参考文献(References)}

[1] REN Rongrong, Zheng Nian, Xing Gang. Research on correlation between science popularization and technological progress. Science Research Management, 2013,(34):290-295.

[2] TONG Hefeng. The Analysis of Science Popularization Policies of People's Republic of China. Science Popularization, 2008, (4): 22-26.

[3] PEI Shi-lan, WANG Li-li, WU Dan, CHEN Chen. The General Situation, Problems and Development Countermeasures of Science Popularization Policy in China. Science Popularization, 2012, (34): 41-48.

[4] SUN Ping, KONG De-yi. Insight into Science and Technology Policy in Shenyang in the 21 st Century. Science and Technology Management Research, 2014, (1): 42-46.

[5] WANG Fang, JI Xue-mei, TIAN Hong. An Informetrics Study on Chinese Rural Informatization Policies. Documentation, Information \& Knowledge, 2013,(1):36-45.

[6] CHEN Yan-tai1, ZHANG Lu-jia,WANG Qin,OU Zhong-hui. Policy evaluation on the development of China's new energy vehicle industry based on Two-stage Model. Science Research Management, 2013, (34):167-174.

[7] HU Sai-hua, ZHAN Zheng-mao, QIAN yue.Studies on the Policy Instrument System about Developing of Strategic Emerging Industry__ Based on Content Analysis of Policies. SCIENTIFIC MANAGEMENT RESEARCH, 2013, (3):66-69.

[8] HUANG Cui,SU Jun,SHI Li-ping,CHENG Xiao-tian. Textual and quantitative research on Chinese wind energy policy system from the perspective of policy tools. Studies in Science of Science, 2011, (6):876-889.

[9] Roy Rothwell, Walter Zegveld. Reindusdalization and Technology. Logman Group Limited, 1985. 83-104.

[10] QIU Jun-ping,WANG Ri-feng. Bibliometric Content Analysis Method. Beijing: National Library of China Publishing House, 2009.47-48.

[11] WANG Xia,GUO Bing, SU Lin. The Analysis of Shanghai Science and Technology Policy Evolution Based on Cotent Analysis.Science \& Technology Progress and Policy, 2012, (23): 104-107.

[12] LI, Yan-ping, WU Shao-tang, GAO Fei, ZHANG Hai-wen. Changes, review and trends ofChina.s scientific research funds managem ent policy since reform and opening up - based on content analysis of policies. Studies in Science ofScience, 2009, (10):1441-1447.

[13] LIU Chun-hua,LI Xiang-fei,ZHANG Zai-Sheng. China's Sports Policy Analysis Based on the Perspective of Policy Instruments. CHINA SPORT SCIENCE, 2009, (10):1441-1447 